Volume (4) No. (2) 2021

دور ممارسة بعض الألعاب الإلكترونية في ارتكاب الجرائم لدى عينة من نزلاء دار الملاحظة الاجتماعية

ماجد عواد العنزي 
دور ممارسة بعض الألعاب الإلكترونية في ارتكاب الجحرائم لدى عينة من نزلاء دار الملاحظة

\section{الاجتحاعية}

$$
\text { ماجد عو اد العنزي }
$$

ماجستير العلوم التربوية، السعودية، alwaely2020@hotmail.com

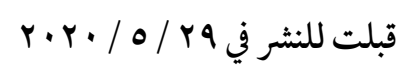

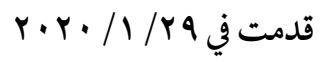

ملخص: انتشر في الآونة الأخيرة، العديد من الألعاب الإلكترونية التي تحاكي الواقع العملي في صورة عالم افتر اضي، مصحوبة بأصوات مرتفعة، وأشكال متنوعة، وصور ملونة، و أدوات وتقنيات مساعدة، والتي تتضمن في خطو اتها ومراحلها، تشجع لاعبيها على ارتكاب الجريمة في صورة احترافية، وتعد القدرة علن تنفيذ الجريمة فعلا، أو الهروب من الوقوع في طائلة القانون، هي مؤشر وعلامة الفوز في

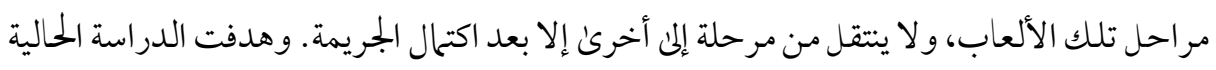
التعرف علئ واقع ممارسة نزلاء دار الملاحظة الاجتماعية للألعاب الإلكترونية، وما إذا كان هناك دور للألعاب الإلكترونية في ارتكاب الجرائم لدىن عينة الدراسة، حيث تم اختيار عينة من نزلاء دار الملاحظة الاجتماعية بالدمام عددها (ع ه) نزيلا، حيث تم إجراء مقابلة شخصية مع عينة الدراسة، واستخدمت الدراسة المنهج الوصفي. وقد توصلت الدراسة إلى عدد من النتائج أهمها: وجود علاقة ايجابية بين ممارسة الألعاب الإلكترونية وشرب الدخان والمخدرات، وأن بعض الألعاب الإلكترونية تساعد علئ إثارة الغرائز الجنسية ونشر الصور والمقاطع المخلة، والمضاربات الشخصية والمطاردات مع الشرطة، كما تساعد بعض الألعاب الإلكترونية في تعليم السرقة والطعن و التفحيط بالسيارات. وقدمت 
الدراسة عدد من التوصيات أهمها ضرورة متابعة أولياء الأمور لألعاب أبناءهم، وضرورة تشديد الرقابة علن أماكن بيع الألعاب الإلكترونية، ومتابعتها على شبكة الإنترنت، والتوعية ضد خخاطرها. الكلمات الدلالية: الألعاب الإلكترونية، ارتكاب الجر ائم، دار الملاحظة الاجتهاعية 


\title{
The Role of Playing Some Electronic Games in Committing Crimes A mong a Sample of House of Social Welfare
}

\author{
Majed Awad Al-Anazi \\ Master of Education, Saudi Arabia, alwaely2020@ hotmail.com
}

\section{Presented in 29 January 2020}

Accepted in 5 May 2020

\begin{abstract}
Recently, many electronic games that simulate practical reality in the form of a virtual world, accompanied by loud sounds, various shapes, color pictures, tools and auxiliary techniques, which include in its steps and stages, encourage players to commit crime in a professional manner, and the ability to actually carrying out the crime, or escaping from falling into the reach of the law, is an indication and a sign of victory in the stages of those games, and it does not move from one stage to another until after the crime is completed. The current study aimed to identify the reality of the practice of House of Social Welfare inmates for electronic games, and whether there was a role for electronic games in committing crimes among the study sample, where a sample of 54 inmates of House of Social Welfare in Dammam was selected, in which a personal interview was conducted with the study sample, and the study used the descriptive method. The study reached a number of results, the most important of which are: a positive relationship between playing electronic games and drinking smoke and drugs, and that some electronic games help to stir up sexual instincts, post pictures and disruptive clips, personal speculations and chases with the police, and some electronic games help teach theft, stabbing and drifting cars. The study made a number of recommendations, the most important of which is the need for parents to follow up on their children's games, and the need to tighten control of places for selling electronic games, follow them on the Internet, and raise awareness against their risks.
\end{abstract}

Key words: Electronic Games, Committing Crimes, House of Social Welfare 
أصبح للألعاب الإلكترونية دور كبير في تغير سلوكيات بعض الأفراد، بل وتجرؤهم على المجتمع بارتكاب بعض الجرائم الاجتماعية، باختلاف شدتها ودرجتها ونوعيتها. ولقد انتشرت في الآونة الأخيرة، تلك الألعاب الإلكترونية التي تحاكي الو اقع العملي في صورة عالم افتراضي، مصحوبة بأصوات مرتفعة، وأشكال متنوعة، وصور ملونة، وأدوات وتقنيات مساعدة، والتي تتضمن في خطو اتها ومر احلها، تشجع لاعبيها على ارتكاب الجريمة في صورة احترافية، وتعد القدرة على تنفيذ الجريمة فعلا، أو الهروب من الوقوع في طائلة القانون، هي مؤشر وعلامة الفوز في مراحل تلك الألعاب، و لا يتتقل من مرحلة إلى أخرى إلا بعد اكتمال الجريمة.

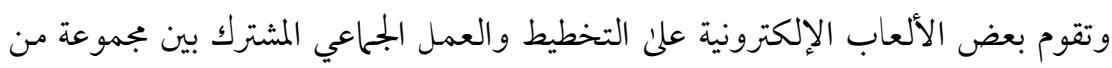
الأفر اد، في أماكن متباعدة، عن طريق التو اصل فيما بينهم، مستخدمين مهارات وعناصر عملية الاتصال المختلفة للوصول إلى الهدف المطلوب، وهو ارتكاب وتنفيذ الجريمة. فالاتصال هو الظاهرة الانسانية التي تجعل الحياة ممكنة، وهو كل ما يجري من علاقات بين بني البشر من تبادل للمعاني وعلن المستويات كافة، وفي كل المجالات، باستخدام الرموز، سواء كانت هذه الرموز لفظية أم غير لفظية، بحيث يمكن

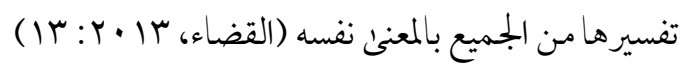

ولعل تطور الألعاب الإلكترونية، وانشارها السريع في الوقت الحاضر، وسط انشغال الآباء و المربين، فضلا عن مؤسسات المجتمع عن التوعية ضد بعض مساوئها وأخطارها، أدى بشكل مباشر وغير مباشر إلى انتشار بعض الجرائم في المجتمع لا يمكن الاستهانة بها أو تجاهلها، لاسيا بين فئات الأطفال والشباب. فقد تكون سببا في تعليم فنيات وتقنيات ارتكاب بعض الجرائم، بغض النظر عن عرف وثقافة المجتمع وقيمه، بل وتصبح -نتيجة إدمانها وكثرة ممارستها- من العوامل التي تشكل شخصيات الأفراد وسلوكياتهم، مزاحمة في ذلك دور كل من الأسرة والمدرسة، بل والمؤسسات

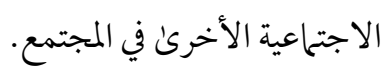




\section{مشكلة البحث:}

يمكن تحديد مشكلة البحث في السؤال الرئيس التالي: ما دور ممارسة بعض الألعاب الإلكترونية في ارتكاب الجرائم لدئ عينة من نزلاء دار الملاحظة الاجتماعية؟

ويتفرع من هذا السؤال الرئيس الأسئلة الفرعية التالية:

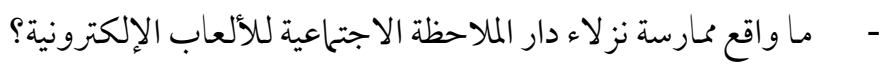

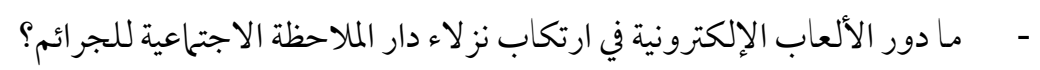

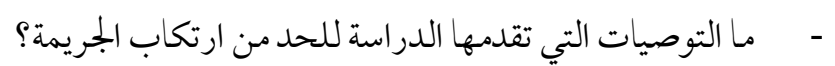

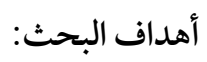

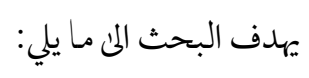
- التعرف على واقع ممارسة نزلاء دار الملاحظة الاجتماعية للألعاب الإلكترونية. - - التعرف على دور الألعاب الإلكترونية في ارتكاب الجرائم لدئ نزلاء دار الملاحظة الاجتماعية. - تقديم التوصيات اللازمة للحد من ارتكاب الجريمة لدى نزلاء دار الملاحظة الاجتماعية. حدود البحث: تقتصر الحدود البشرية للبحث الحالي على نزلاء دار الملاحظة الاجتماعية، وذلك خلال الفصل

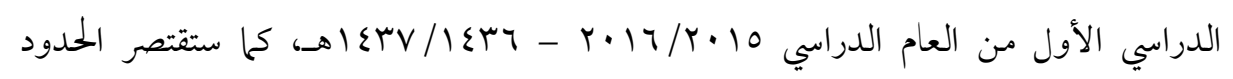
الموضوعية للبحث علن جانب ممارسة الألعاب الإلكترونية فقط. أهمية البحث: يمكن توضيح أهمية البحث الحالي فيا يلي: ا - مواجهة مشكلة العنف لدئ فئة الشباب والتي قد تتسرب إليهم من خلال الألعاب الإلكترونية 
r- لفت انتباه أولياء الأمور المربين وأصحاب القرار إلى ضرورة متابعة محتويات الألعاب

$$
\text { الإلكترونية والتصدي لما بها من سموم. }
$$

r- - وضع أولياء الأمور والمربين وأصحاب القرار أمام الوضع الحالي للألعاب الإلكترونية ومـا

$$
\text { قد تسببه من انتشار الجريمة لدئ فئات الشباب }
$$

$$
\text { منهج الدراسة للبحث الحالي: }
$$

يستخدم البحث المنهج الوصفي لمناسبته لموضوع الدراسة، وذلك في وصف وجمع وتحليل البيانات المتعلقة بممارسة نز لاء دار الملاحظة الاجتماعية للألعاب الإلكترونية، وتحليل أثر ممارسة تلك الألعاب على ارتكابهم للجرائم، ثم تقديم المقترحات والتوصيات اللازمة، بناء علن ما ستسفر عنه نتائج الدراسة، للتقليل من الآثار السلبية لمارسة بعض الألعاب الإلكترونية، الأمر الذي قد يقلل من

$$
\text { ارتكاب الجرائم، ويعود بالأمن علن جميع أفراد المجتمع. }
$$

$$
\text { أدوات البحث: }
$$

استخدم البحث المقابلة الشخصية: وذلك مع عينة الدراسة، للتعرف علئ أهم أسباب توقيفهم في دار الملاحظة الاجتحاعية، والتعرف علئ ما إذا كانت هناك علاقة بين ممارستهم للألعاب الإلكترونية وتوقيفهم في دار الملاحظة الاجتماعية. مصطلحات البحث: تتمثل أهم مصطلحات البحث فيما يلي: - اللعب: اللعب عملية ذاتية يقوم بها الطفل عن اختيار، وهو موجه للسلوك الشخصي، ويزود الفرد بالرضا والارتياح، ويساعد الفرد علن التعلم والتطوير ذاتيا، ومن هنا فقد تعددت تعريفات اللعب حسب وجهة النظر التي يتم من خلالها تعريفه، ومن تعريفات اللعب ما يلي: 1. يعرّف كاليوس Caillios اللعب بأنه نشاط حر يمارس بدون قهر، ويؤدي إلى السرور

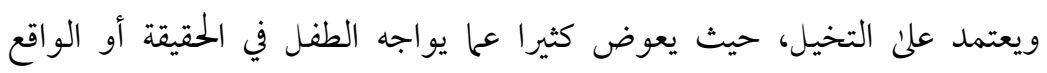

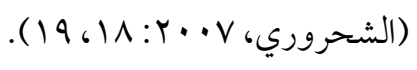

http://dx.doi.org/10.29009/ijres.4.2.8 
r. ويعرف معجم مصطلحات التربية اللعب لفظا واصطلاحا بأنه "اشتراك الفرد في نشاط رياضي أو ترويجي، واللعب قد يكون حرا أي يأتي عن دافع طبيعي، كما قد يكون منظما

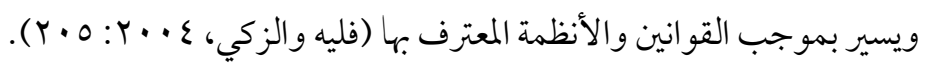

- الألعاب الإلكترونية: هي نشاط منظم يتم اختياره وتوظيفه لتحقيق أهداف محددة أهمها

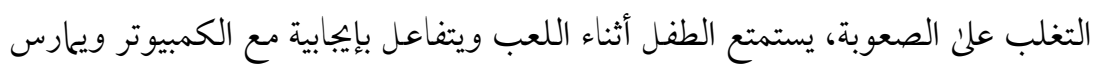

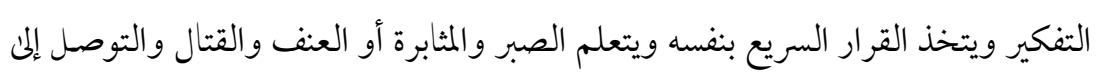

$$
\text { نتائج معززة (مطاوع، ، ... ب: 0). }
$$

- دار الملاحظة الاجتماعية: هي "دار إيوائية تسعنى لتحقيق أسس الرعاية والتوجيه الخلقي

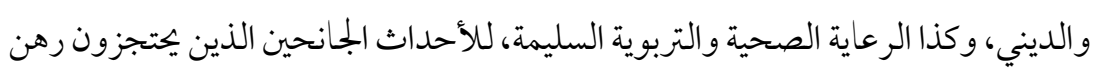

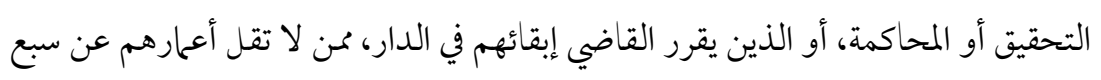
سنوات ولا تتجاوز ثلاني عشرة سنة، ممن يتم القبض عليهم من قبل السلطات الأمنية المخولة بالقبض والإيقاف، لارتكابهم أي مخالفات تستوجب تأديبهم، وتتحدد مدة الحجز بتلك

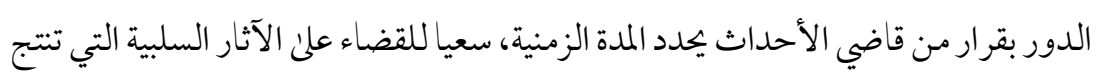

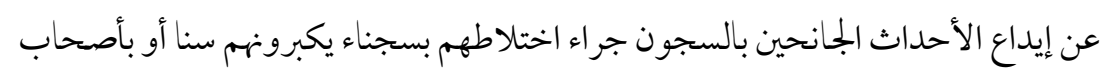

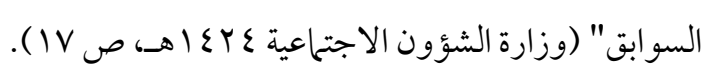

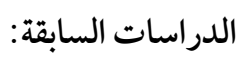

تناولت دراسة عبد المحسن عمار المطيري (ج · ㄱ) تحديد حجم ظاهرة العنف الأسري في مجتمع الدراسة، والعلاقة بين العنف الأسري وانحر اف الأحداث، ومحاولة التوصل إلى تدابير وقائية من شأنها أن تحد من تأثير العنف الأسري علن انحر اف الأحداث، وتوصلت الدراسة إلى عدة نتائج أهمها: - - نسبة من يعانون من العنف الأسري منخفضة. - السرقة هي أبرز الأسباب التي بسببها تم ايداع الأحداث دار الملاحظة الاجتماعية. 
- من أبرز أنماط العنف الأسري لدئ العينة هو العنف اللفظي. - معظم أفر اد العينة قامو ابارتكاب الفعل المنحرف برفقة أصدقائهم.

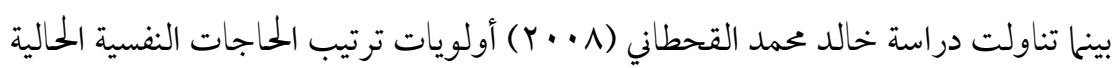
للأحداث الجانحين بدار الملاحظة الاجتماعية، وعلاقتها بالفئات العمرية ومهنة الوالدين والمستوىن التعليمي للو الدين، وتوصلت إلى عددمن النتائج أهمها: - أعلن نسبة إلحاح لدئ الأحداث تمثلت في تحقير الذات ولوم الذات. - لا توجد فروق دالة احصائيا للحاجة النفسية تعود لاختلاف مهنة الاباء للأحداث. - - موجد فروق دالة احصائيا في الحاجات النفسية تعود لاختلاف المستوئ التعليمي للأمهات لصالح الأم التي تحمل شهادة الثانوية.

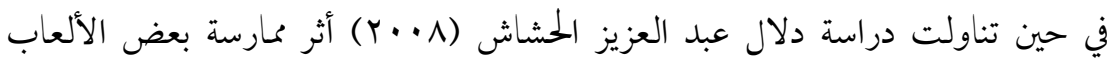
الإلكترونية في السلوك العدواني لدىن طلبة المرحلة الثانوية في المدارس الحكومية بدولة الكويت، وتوصلت الدراسة إلى وجود فروق ذات دلالة إحصائية بين متوسط درجات طلبة المجموع التجريبية ومتوسط درجات طلبة المجموعة الضابطة في السلوك العدواني لدىن طلبة المرحلة الثانوية في المدارس الحكومية بدولة الكويت تعزئ لأثر ممارسة بعض الألعاب الإلكترونية، ولصالح طلبة المجموع التجريبية.

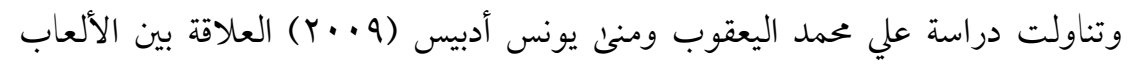
الإلكترونية وسلوك العنف لدى الأطفال في المرحلة الابتدائية، وبين الألعاب الإلكترونية وجنس الطفل، والمدة الزمنية التي يقضيها الطفل في اللعب بالألعاب الإلكترونية ودرجة العنف لديه. وتوصلت إلى عدد من النتائج أهمها: - وجود علاقة بين الألعاب الإلكترونية والعنف لدىن عينة من أطفال المرحلة الابتدائية في دولة الكويت. - أن هذه الألعاب لها دور في تنمية سلوك العنف لديهم. 
- ل ل للألعاب الإلكترونية عدد من المخاطر علن صحة الطفل، منها التعرض لشاشة الكومبيوتر

$$
\text { لفترات طويلة ممايؤثر علن الجهاز البصري. }
$$

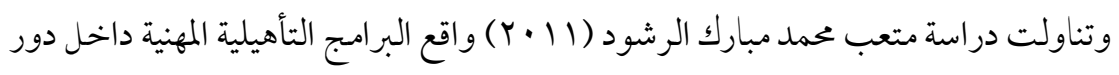

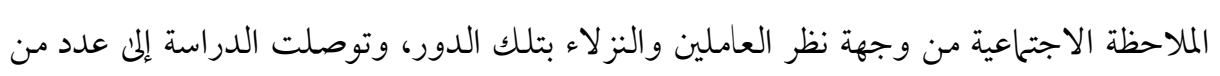

$$
\text { النتائج اهمها: }
$$

- - تتجه دور الملاحظة نحو تفعيل البرامج المهنية المتعلقة بالميكانيكا والكهرباء والنجارة في أغلب

$$
\text { الأحوال. }
$$

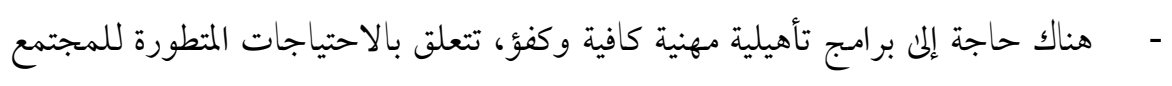

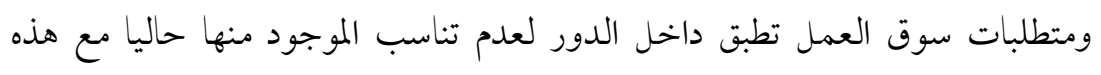

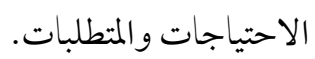

- حاجة المرشدين الطلابيين في دور الملاحظة الاجتماعية إلى مزيد من التدريب فيما يتعلق بالتأهيل المهني.

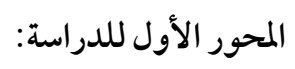

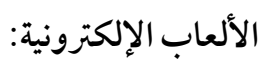

مع بداية الثمانينات، ومع التطور التكنولوجي واستخدامات الحاسوب المتعددة، برزت أشكال

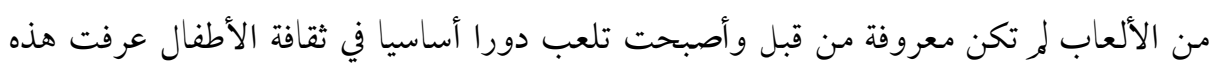

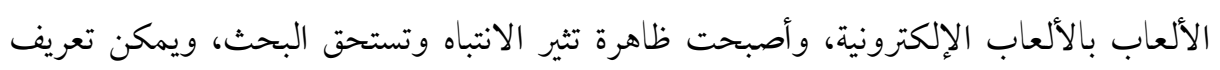

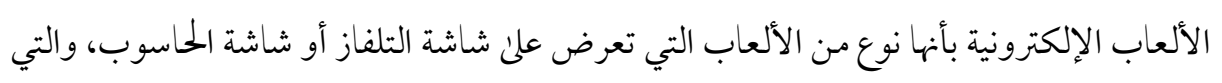

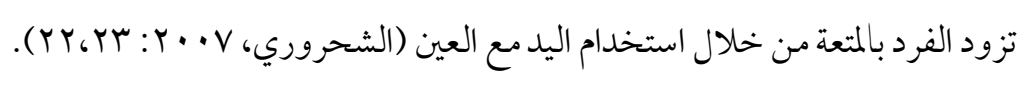

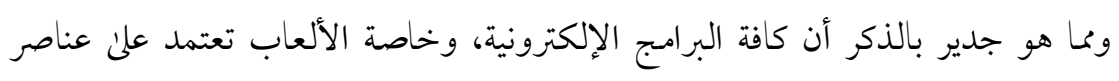

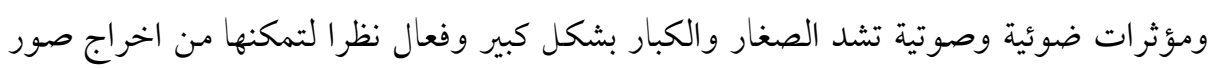


وألو ان معينة قد لا يتمكن خخرجو التلفاز من تنفيذها، خاصة بعد إضافة الابعاد الثلاثية والمؤثرات الصوتية لها. فلا تكاد تخلو ثقافة انسانية أو عصر من عصورها، من ممارسة نوع من أنواع الألعاب التي تختلف في طبيعتها ودرجة خطورتها وعدد لاعبيها، إلا أنها تتفق جميعا على مبدأ واحدو وهو الإثارة وإبراز القدرات الفردية، مما يدفع كل فردمن أفراد المجتمع تقريبا إلى ممارسة نوع منها في فترة من فترات عمره

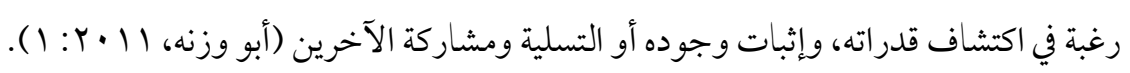
فقد انتشرت في الآونة الأخيرة الألعاب الإلكترونية بسرعة هائلة في المجتمعات العربية بوجه عام والخليجية بوجه خاص، حتى أصبحت جزءًا من غرفة الطفل، بل أصبح الآباء والأمهات يصطحبونها معهم أينما ذهبو اليزيدوا من إدمان أطفالهم علن ممارستها دون أن يدروا. ولا يقتصر انتشار الألعاب الإلكترونية على فئة الأطفال، بل يمتد الأمر ليشمل مرحلة المراهقة و الشباب، فضلا عن انشارها علن المستوى العالمي والمحلي وفق سيادة النظام العالمي، الذي ينفي في طياته أهدافا كثيرة تحتاج في تحقيقها إلى نشر سلوكيات وقيم محددة منها حب الذات، والرغبة في السيطرة و التملك، وحب استهلاك كل ما هو جديد، وعدم الرغبة في المحافظة على كل ما هو متوفر، والنفور من سلوكيات وعادات وتقاليد المجتمعات المحلية ووصفها علن أنها رجعية بالية (المولن والعبيدي، .$(7 \cdot 9: r \cdot 1 r$ ولقد أضحت مشاهد العنف والجريمة جزءا لا يتجزأ من الحياة اليومية لمن يمارس الألعاب الإلكترونية، بل ويتلذذ بالمشاهد العنيفة المرتبطة شرطيا بالبطل الأكثر قوة وعنفا وقسوة من خلال أداء استعر اضي يجسده افتراضيا من خلال اللعب، ومما ييسر اكتساب السلوك العدواني وتعلم خطواته

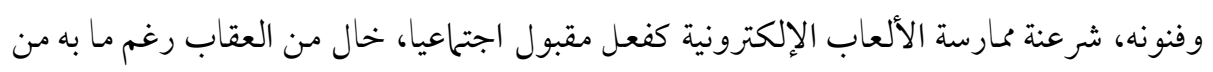

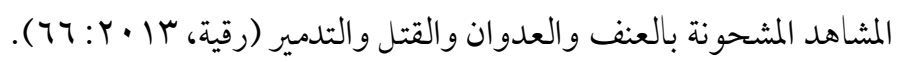

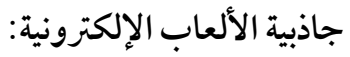


تتميز الألعاب الإلكترونية بعوامل جذب وتشويق للكثيرين من الأفراد في الأعمار المختلفة (الأطفال، والمراهقين، والشباب، والكبار)، ومن هذه العو املل التي تميزها عن غيرها من الألعاب مـا

1- الدقة والجودة في تصميم وتنسيق الألو ان والأشكال والصور. r- التفاعلية من خلال بيئة افتراضية تحاكي الواقع.

ب- توفر المؤثرات الصوتية عالية الدقة المصاحبة للألعاب، مما يشجع على الاستمرار. ع - - اعتمادها علن المرحلية والتدرج. 0- المشاركة الجماعية مع الآخرين وتحقيق المنافسة. 7- المكافئات الفورية لاجتياز كل مرحلة. - V - القدرة على جذب الانتباه لدرجة التوحدمع اللعبة. ^- الإثارة والمتعة، مما يسبب معها الإدمان. فو ائد الألعاب الإلكترونية: للألعاب الإلكترونية عدة فوائد لمن يقوم بممارستها منها: - - زيادة التآزر البصري الحركي r- ت تعليم القدرة علن اتخاذ القرار خلال وقت قصير. r- - توقع حدوث الأخطاء وكيفية مواجهتها. ع - التخطيط للوصول إلى الفوز ونهاية المرحلة. ه- المساهمة في النمو المعرفي والاجتحاعي والانفعالي للطفل، وتطوير شخصيته بشكل عام.

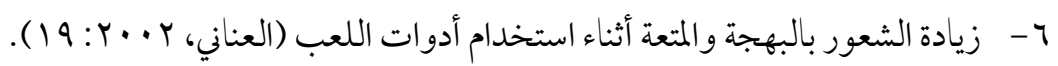
أضرار الألعاب الإلكترونية: كما أن للألعاب الإلكترونية فو ائد، فإن لها العديد من الأضرار منها:

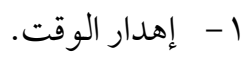
ץ- الوصول إلى درجة الإدمان مما يؤثر على الناحية العلمية والشخصية للفرد. r- بأثيرها علن صحة العين. 
ع- الجلوس لفترة طويلة بوضع معين، مما قد يسبب تشوها في العمود الفقري أو القنص

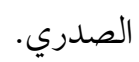
ه- زيادة العدوان و الانععالات العدوانية لدئ المارسين لها.

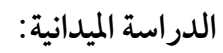
هدف الدراسة الميدانية وأداتها: - مل تهدف الدراسة الميدانية وأداتها إلى جمع بيانات من عينة الدراسة حول العلاقة بين ممارسة الألعاب الإلكترونية وارتكاب الجرائم، وذلك من خلال عدد من الأسئة التي تم توجيهـا لأفراد عينة الدراسة، التي تم اختيارها بطريقة عشوائية، حيث تم إجراء المقابلة الشخصية مع جميع أفراد العينة على الن مدار أربع جلسات في يومين، تراوحت كل منها ما بين ساعة وساعة ونصف، حيث قام الباحث بتو جيه الأسئلة إلى أفر اد عينة الدراسة ويتتظر إلى سماع الردمن كل فرد ثم يدونه، ويستمع من الآخر وهكذا، وقد كان الباحث يستخدم معهم أسلوب التشجيع علن التحدث من خلال كلمات المدح والثناء لكل من يقول رأيه بناء علن الو اقع الفعلي الذي عايشه.

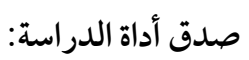
قام الباحث بحساب صدق الأداة من خلال صدق المحكمين، وذلك بإعداد استمارة مقابلة شخصية تحتوي علن جز أين: الجزء الأول: ويحتوي على البيانات الأساسية لعينة الدراسة. الجزء الثاني: ويحتوي علن مجموعة من الأسئلة التي تتعلق بمتغيري الدراسة الأساسيين وهما متغير الألعاب الإلكترونية، ومتغير الجرائم، حيث قام الباحث بوضع الأسئلة تحت أربعة محاور في كل منها

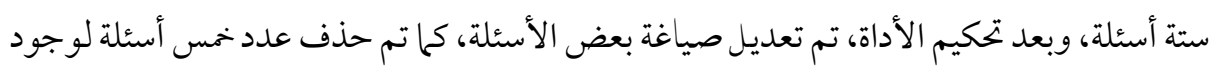
التداخل فيما بينها، وأصبحت الأداة في صورتها النهائية مكونة من وب سؤ الا. 


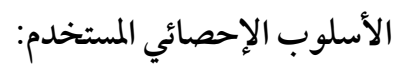

استخدم الباحث أسلوب التكرارات والنسب المئوية، وذلك لمناسبتها لهدف الدراسة، وتحليل البيانات المتحصلة من المقابلة الشخصية، وذلك للوقوف علن دور الألعاب الإلكترونية في ارتكاب الجريمة لدى نز لاء دار الملاحظة الاجتماعية. نتائج الدراسة الميدانية: - n بلغ عدد النزلاء في يوم وتاريخ تطبيق أدوات الدراسة (0 • 1) نزيلا، وتم أخذ عينة عشوائية منهم عددها (ع ه) نزيلا بنسبة قدرها (101\%) من العدد الكلي، حيث تم عقد عدد أربع جلسات مع عينة الدراسة خلال يومين(")، لكي يتمكن الباحث من تدوين كل المعلومات التي يكصل عليها من أفراد العينة، وقد حرص الباحث أن تتم جميع جلسات المقابلات الشخصية مع أفراد العينة في حضور أحد المشرفين في الدار.

تجيب نتائج الدراسة علن كل من السؤال الثاني والثالث من أسئلة الدراسة، وهو ما يتم تناوله من خلال كل من المحور الثاني والمحور الثالث للدراسة، كما توضح نتائج الدراسة بعض البيانات الأساسية لعينة الدراسة. فمن خلال استمارة المقابلة الشخصية التي طبقت علن عينة الدراسة، والتي تهدف إلى جمع بيانات حول العلاقة بين ممارسة الألعاب الإلكترونية وارتكاب الجريمة، بالإضافة إلى بعض البيانات الأساسية، تتضح نتائج الدراسة وذلك فيما يلي: 1- المرحلة العمرية: فيما يتعلق بالمرحلة العمرية لأفراد العينة، فإن الجمدول التالي يوضح العمر بالسنوات ونسبة كل منها لدئ أفر ادعينة الدراسة.

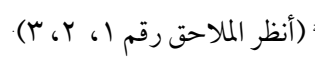

http://dx.doi.org/10.29009/ijres.4.2.8 


\section{جدول (1) المرحلة العمرية لأفراد عينة الدراسة}

\begin{tabular}{|c|c|c|c|}
\hline$\%$ & العدد & العمر (بالسنوات) & p \\
\hline$r, v$ & r & $1 \varepsilon$ & 1 \\
\hline $1 r, \cdot$ & V & 10 & r \\
\hline 17,7 & 9 & 17 & $r$ \\
\hline$\{\tau, r$ & ro & IV & $\varepsilon$ \\
\hline$r \cdot, \varepsilon$ & 11 & 11 & 0 \\
\hline$\% 1 \cdots$, & $0 \varepsilon$ & الإجمالي & \\
\hline
\end{tabular}

ويتضح من الجدول السابق أن أعلى نسبة من أفراد العينة هي في المرحلة العمرية (V سنة)، بنسبة قدرها

\section{$(\%\{\uparrow, r)$}

r- المرحلة التعليمية: فيا يتعلق بالمرحلة التعليمية لأفر اد العينة، فإن الجحدول التالي يوضح المرحلة

$$
\text { التعليمية ونسبة كل منها لدئ أفراد عينة الدراسة. }
$$

جدول (Y) المرحلة التعليمية لأفراد عينة الدراسة

\begin{tabular}{|c|c|c|c|}
\hline$\%$ & العدد & المرحلة التعليمية & p \\
\hline$\cdot, \cdot$ & . & الابتدائية & 1 \\
\hline Yr, r & ir & المتوسطة & r \\
\hline$V r, r$ & rq & الثانوية & $r$ \\
\hline 0,7 & $r$ & أخرى (تسرب من & $\varepsilon$ \\
\hline$\% 1 \cdots$, & $0 \varepsilon$ & الإجمالي & \\
\hline
\end{tabular}

ويتضح من الجدول السابق أن أعلى نسبة من أفراد العينة هي في المرحلة التعليمية الثانوية، بنسبة قدرها $(\%$. $(\%, r)$

r- أسباب الوقوع في الجريمة: وبالرجوع إلى أسباب الوقع في الجريمة، فإن الجدول التالي يوضح تلك الأسباب حسب مـا أفاد به أفر اد عينة الدراسة ونسبة كل منها.

\section{http://dx.doi.org/10.29009/ijres.4.2.8}




\begin{tabular}{|c|c|c|c|}
\hline$\%$ & 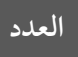 & السبب & p \\
\hline rr, r & ir & المشاكل الأسرية & 1 \\
\hline rr, r & 11 & الصحبة السيئة & r \\
\hline$r \cdot, \varepsilon$ & 11 & الألعاب الإلكترونية & r \\
\hline ir, & v & المشكلات الاقتصادية & $\varepsilon$ \\
\hline$\vee, \varepsilon$ & $\varepsilon$ & إثبات الذات & 。 \\
\hline$r, v$ & r & أخرى & 7 \\
\hline$\% 1 \cdots$, & of & الإجمالي & \\
\hline
\end{tabular}

ويتضح من الجدول السابق أن الصحبة السيئة هي من أكبر أسباب وقوع أفراد العينة في

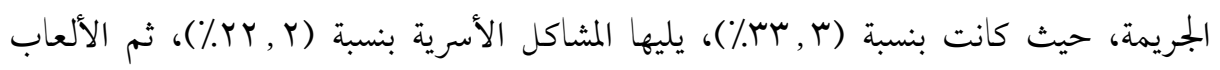
الإلكترونية بنسبة (ع , ·r٪)، وهي نسبة لا يستهان بها، خصوصامع انتشار تلك الألعاب وتغافل الآباء وأولياء الأمور عن مضمونها، وعن متابعة أبنائهم.

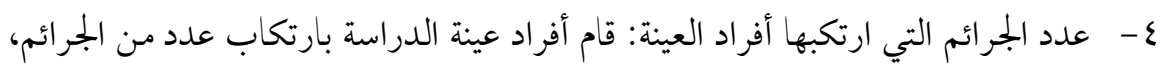
حيث تم ايقافهم بناء عليها، فضلا عن عدد آخر من الجرائم التي لمريتم ايقافهم عليها.

$$
\text { ويوضح الجلدول التالي تلك الجرائم وعددها. }
$$$$
\text { جدول (ع ) عدد الجرائم التي ارتكبها أفراد العينة وتم ايقافهم عليها }
$$

\begin{tabular}{|c|c|c|c|}
\hline$\%$ & العدد & بجال الجريمة & b \\
\hline \% Yr, r & ir & خدررات & 1 \\
\hline$\% \varepsilon \varepsilon, \varepsilon$ & $r \varepsilon$ & أخلاقية & r \\
\hline$\%, r$ & 0 & عنف & $r$ \\
\hline$\%$ \% $\{, 1$ & ir & سرقة & $\varepsilon$ \\
\hline$\% \ldots$, & $0 \varepsilon$ & الإجمالي & \\
\hline
\end{tabular}


ويتضح من الجدول السابق أن أكثر عدد جرائم لأفراد العينة كان للجرائم الأخلاقية بنسبة

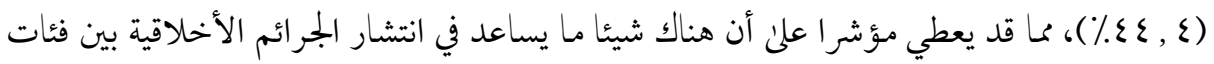

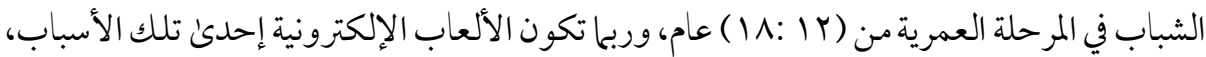

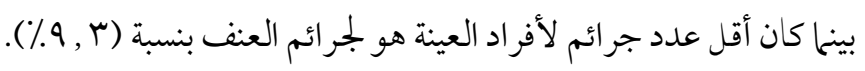
المحور الثاني للدراسة: التعرف على واقع ممارسة نزلاء دار الملاحظة الاجتماعية بالدمام للألعاب الإلكترونية من خلال استخدام أداة الدراسة وهي المقابلة الشخصية، مع عينة من نزلاء دار الملاحظة الاجتماعية، حيث يجيب هذا المحور علي السؤال ما واقع ممارسة نزلاء دار الملاحظة الاجتماعية للألعاب

الإلكترونية؟

وتتضح الإجابة علن هذا السؤال من خلال بيان خبرة أفر ادعينة الدراسة بالألعاب الإلكترونية

$$
\text { من حيث عدد سنوات معرفتهم بالألعاب الإلكترونية، وذلك كما يلي: }
$$

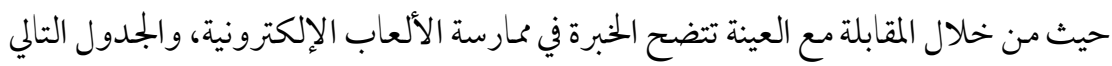
يوضح عدد السنوات التي قام بها أفر اد العينة بممارسة الألعاب الإلكترونية ونسبة كل منها. جدول (0) الخبرة بالسنوات بالألعاب الإلكترونية لأفراد العينة

\begin{tabular}{|c|c|c|c|}
\hline$\%$ & العدد العد & المدة بالسنوات & b \\
\hline 1,1 & 1 & من · إلى أقل من r & 1 \\
\hline $9, r$ & o & من r إلى أقل من ع & r \\
\hline $17, V$ & 9 & من ع إلى أقل من 7 & r \\
\hline$r \varepsilon, 1$ & ir & من 7 إلى أقل من ^ & $\varepsilon$ \\
\hline$r \cdot, \varepsilon$ & 11 & من ^ إلى أقل من · 1 & $\circ$ \\
\hline$r V, \Lambda$ & 10 & من · ا إلى أقل من r I & 7 \\
\hline$\cdot, \cdot$ & . & أكثر من r ا سنة & $\checkmark$ \\
\hline$\% 1 \cdots$, & $0 \varepsilon$ & الإجمالي & \\
\hline
\end{tabular}

ويتضح من الجمدول السابق أن أكثر أفراد العينة لديهم خبرة في ممارسة الألعاب الإلكترونية من

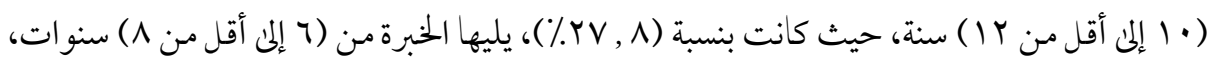


بنسبة (1 , ع Y\%)، بينما كانت أقل نسبة لعدد أفر اد العينة الذين لديهم خبرة من (• إلى أقل من Y) سنة،

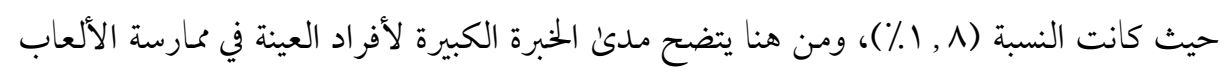

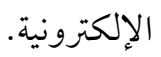
المحور الثالث للدراسة: توضيح دور ممارسة الألعاب الإلكترونية في ارتكاب الجريمة لدني عينة من

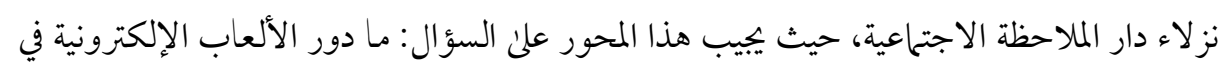
ارتكاب نز لاء دار الملاحظة الاجتماعية للجرائم؟

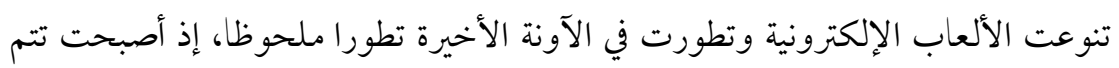

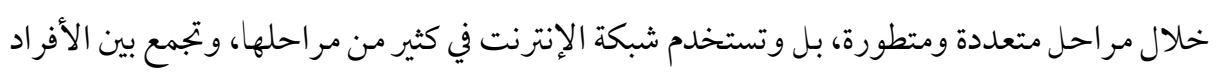

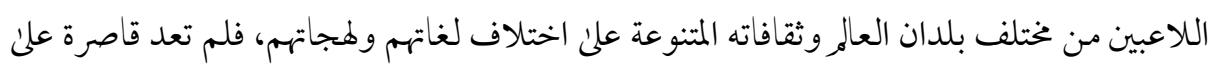

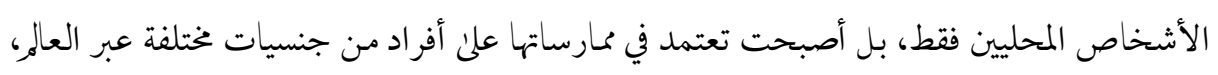

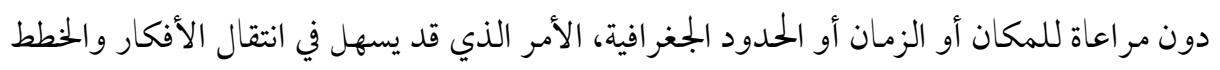

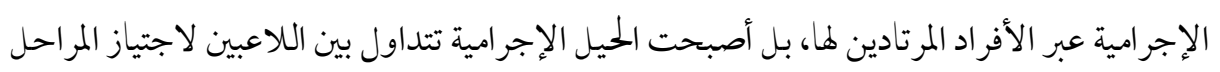
المختلفة من اللعبة والوصول إلى المراحل المتقدمة منها. وللإجابة علن السؤال: ما دور الألعاب الإلكترونية في ارتكاب نز لاء دار الملاحظة الاجتماعية.

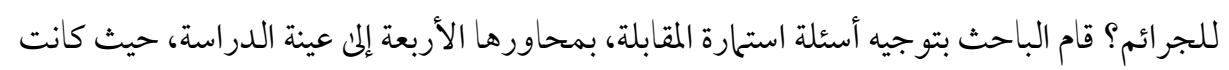
أولا: محور الجرائم التي تتعلق بالمخدائت لتحرات الأداة كما يلي: جدول (7) استجابات عينة الدراسة حول المحور الثاني (المخدرات)

\begin{tabular}{|c|c|c|c|c|c|c|c|c|}
\hline الوزن & & & & & افق & & & \\
\hline النسبي & $\%$ & ت & $\%$ & ت & $\%$ & ت & & 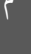 \\
\hline$r, 1 \wedge$ & $\varepsilon \cdot, v$ & $r$ & $\therefore$ & . & $\circ 9, r$ & rr & المسهرة:؟ تساعد الألعاب الإلكترونية في تناول الحبوب & 1 \\
\hline $1, \Delta v$ & $\varepsilon \eta, r$ & ro & $r, \varepsilon$ & 11 & $r r, r$ & 11 & هل هل تشجع الألعاب الإلكتورنية علن تعطي & r \\
\hline
\end{tabular}




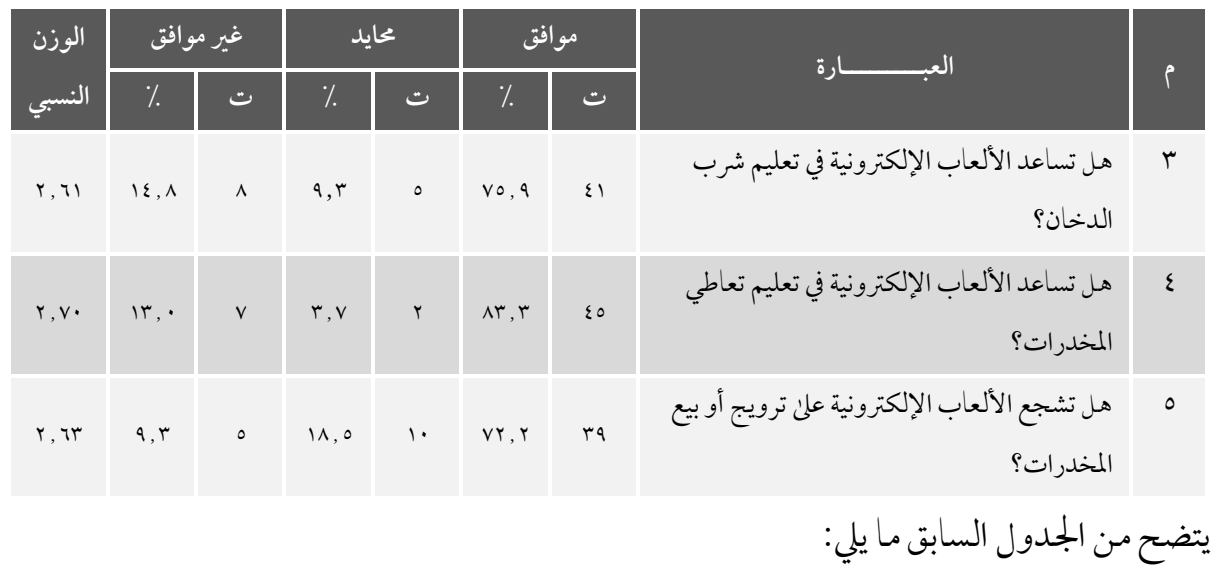

ا - عند الاجابة علن السؤال: هل تساعد الألعاب الإلكترونية في تناول الحبوب المسهرة؟ كانت

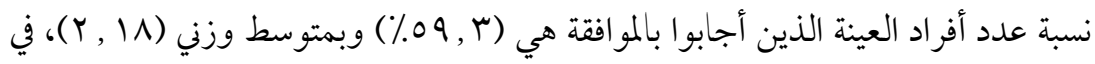
حين كانت نسبة عدد أفراد العينة الذين أجابوا بعدم الموافقة علن السؤال هي (V, • ع.٪). وتعد نسبة عدم الموافقة كبيرة بالمقارنة بنسبة الموافقة، وربها يرجع ذلك إلى أن طبيعة الألعاب الإلكترونية ونوعيتها تمثل عامل جذب ولفت الانتباه لمن يقوم بممارستها، نظر الما تحتويه من أصوات صاخبة وصور و ألوان جذابة، كما أن معظم أفر اد العينة أفادوا بأنهم يلعبون الألعاب الإلكترونية في المنزل، وربها يخشون من معاقبة أولياء أمو رهم لهم في حالة معرفتهم بتناولهم

r- عند الاجابة علن السؤال: هل تشجع الألعاب الإلكترونية على تعاطي الحبوب المخدرة؟

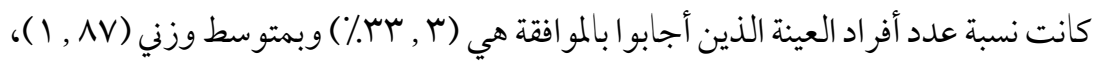

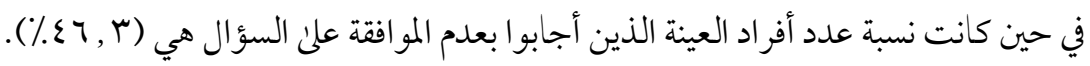
وتعد نسبة عدم المو افقة كبيرة جدا بالمقارنة بنسبة المو افقة، بل هي أكبر منها، وربها يرجع ذلك إلى أن معظم أفر اد العينة أفادوا بأنهم يلعبون الألعاب الإلكترونية في المنزل، وربها يخشون من معاقبة أولياء أموروهم لهم في حالة معرفتهم بتناولمم للجبوب المخدرة، كما أن تناول الحبوب المخدرة في الغالب يكون في وجودصححبة من الأصدقاء ويحتاج إلى تشجيع منهم وهو ما لا 
يتو افر في حالة ممارستهم الألعاب بالمنزل. ويمكن تفسير ارتفاع نسبة عدد المو افقين على أن الألعاب الإلكترونية تشجع على تناول الحبوب المخدرة، ربها يرجع ذلك إلى ما أفادت به نسبة كبيرة من أفراد العينة بأنهم يفضلون اللعب مع زملائهم الذين تحصص هم أولياء أمورهم

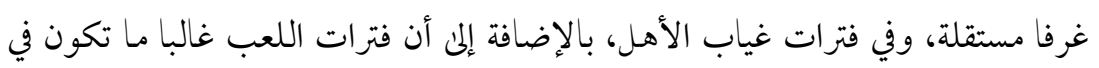

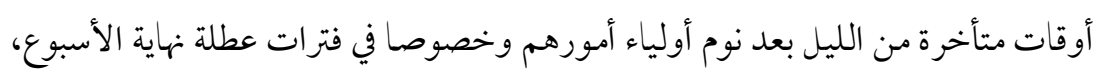
أو ربها يفضلون اللعب في محلات الألعاب الإلكترونية، التي ربها لا تتو افر فيها الرقابة الكافية على مرتاديها.

r- - توجد عند الاجابة علن السؤال: هل تساعد الألعاب الإلكترونية في تعليم شرب الدخان؟

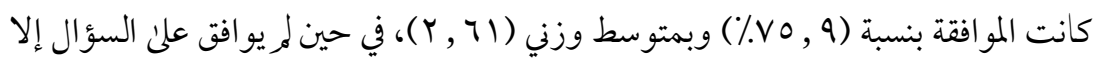
نسبة (^, ع (1\%). وتعد نسبة الموافقة كبيرة، مقارنة بنسبة عدم الموافقة، وربها يرجع ذلك إلى أن اللاعبين يحاولون تقليد بعض الشخصيات التي يشاهدونها في ألعابه، كما أن تواجد اللاعبين في غرف مستقلة ولأوقات متأخرة من الليل ربما تكون عاملا مشجعا هم علئ التدخين وخاصة إذا كانوا في محلات الألعاب الإلكترونية.

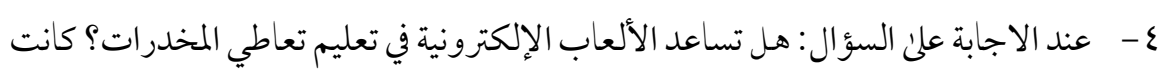
المو افقة بنسبة (r, r.

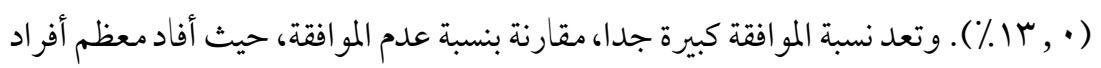
العينة بأن هناك بعض الألعاب الإلكترونية تعلم طرق تعاطي المخدرات، بل وارتكاب جميع

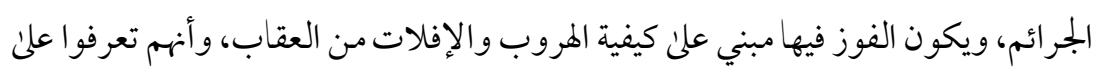
أنواع المخدرات من تلك الألعاب، بل وكيفية تعاطيها.

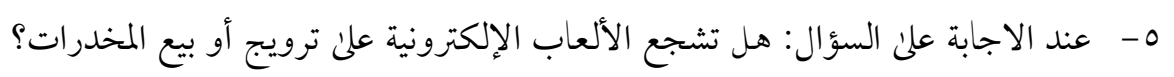

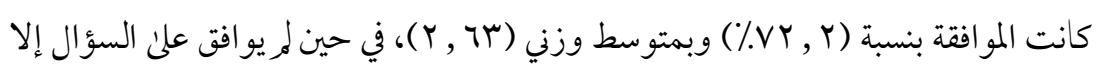

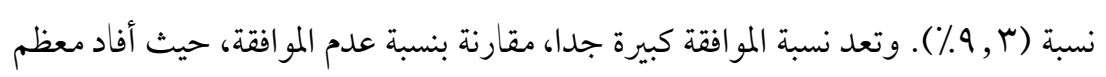


أفراد العينة بأن هناك بعض الألعاب الإلكترونية التي تعلم طرق تعاطي المخدرات وبيعها وترويجها لتحقيق المكاسب المادية، ويكون الفوز فيها مبني علن مقدار المبالغ المحصلة من البيع وشراء الأشياء الأخرىن. ونظر اللمكاسب المادية التي يحققها اللاعب أثناء اللعبة، فإنه يكون مهيئا للتجريب في الو اقع فيكون ضحية لقرناء السوء مـن يروجون ويبيعون المخدرات، فينضم إلى قافلة المروجين ليحصل علن الجرعة التي يريدها نظير بيعه أو ترويجه للمخدرات، أو تجنيده للأفراد الجلدد، فتكون مكافأته هي الحصول علن المخدر بلا مقابل مادي. ثانيا: محور الجرائم الأخلاقية:

جدول (V) استجابات عينة الدراسة حول المحور الثالث (الأخلاقية)

\begin{tabular}{|c|c|c|c|c|c|c|c|c|}
\hline الوزن & & & & & & & & \\
\hline النسبي & $\%$ & ت & $\%$ & 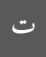 & $\%$ & ت & - & $\Gamma$ \\
\hline$r, r r$ & $r_{1,0}$ & IV & $1 \varepsilon, \wedge$ & $\wedge$ & or, $v$ & ra & هل جل تساعد الألعاب الإلكترونية في ارتكاب & 1 \\
\hline$r, \wedge 1$ & 0,7 & $r$ & $v, \varepsilon$ & $\varepsilon$ & $\wedge \mathrm{v}, \cdot$ & $\varepsilon V$ & 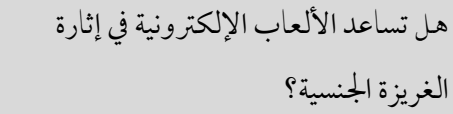 & r \\
\hline$r, v^{\prime}$ & $\cdot, \cdot$ & . & 1,9 & 1 & १^, । & or & هل تساعد الألعاب الإلكترونية في نشر & r \\
\hline$r, \tau \wedge$ & $\cdot, \cdot$ & . & 0,7 & $r$ & १६, ६ & 01 & هل المقاطع الجنسية الألعاب الإلكترونية في نشر & $\varepsilon$ \\
\hline$r, r \Lambda$ & $r q, 7$ & 17 & ir, & $v$ & $\circ v, \varepsilon$ & $r_{1}$ & هل تشجع الألعاب الإلكترونية على ارتكاب & 0 \\
\hline
\end{tabular}

ا - عند الاجابة علئ السؤال: هل تساعد الألعاب الإلكترونية في ارتكاب جريمة الابتز از؟ كانت

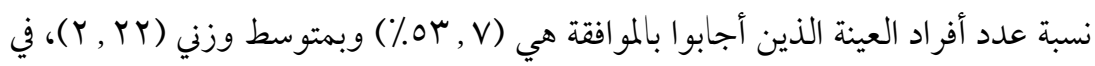
حين كانت نسبة عدد أفراد العينة الذين أجابوا بعدم الموافقة علن السؤال هي (ه , آبـ).

\section{http://dx.doi.org/10.29009/ijres.4.2.8}


وربها يفسر ذلك بأن معظم أفراد العينة يحرصون علن الألعاب التي تعتمد علن العنف والمطاردات، كما أن جريمة الابتزاز هي من الجرائم التي تحتاج إلى نوعية خاصة من الأفراد

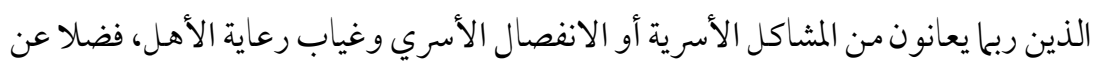
التخطيط والحرص لتنفيذ الجريمة. وتعد نسبة عدم الموافقة كبيرة جدا بالمقارنة بنسبة الموافقة، وربها يرجع ذلك إلى أن معظم أفراد العينة ما زالوا بخير من الناحية الأخلاقية، ويعتبرون

$$
\text { الابتزاز من الأشياء المحرمة جدا. }
$$

r- عند الاجابة علن السؤال: هل تساعد الألعاب الإلكترونية في إثارة الغريزة الجنسية؟ كانت

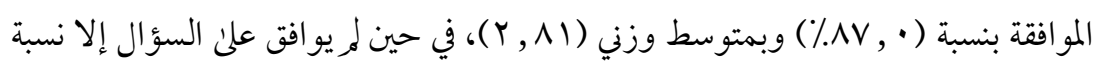

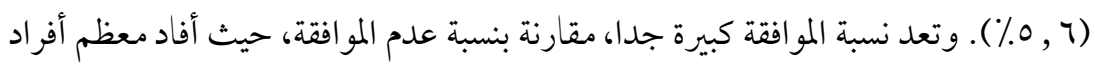
العينة بأن معظم الألعاب الإلكترونية تحتوي على صور غير أخلاقية للنساء، وكثير من المشاهد التي تثير الغريزة الجنسية، بل إن بعض الألعاب الإلكترونية تتطلب من لاعبيها لكي ينتقل إلى مرحلها المتقدمة أن يقوم بممارسة الرذيلة مع الشخصية الكرتونية باللعبة، ثم ينتقل إلى المرحلة الأخرى المتقدمة منها. ץ- عند الاجابة علن السؤال: هل تساعد الألعاب الإلكترونية في نشر الصور الجنسية؟ كانت

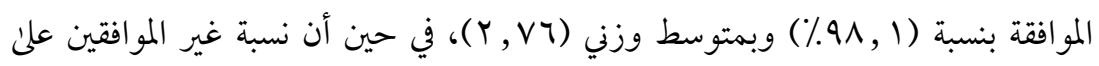
السؤال تصل إلى الصفر . وتعد نسبة المو افقة علن السؤال كبيرة جدا، حيث يكاد يجمع أفراد العينة علن أن معظم الألعاب الإلكترونية تحتوي علن الصور والمشاهد الجنسية، وصور للنساء في أوضاع غير أخلاقية، حيث تظهر الصور في المراحل المختلفة من اللعبة وفي أثناء اللعبة،مع

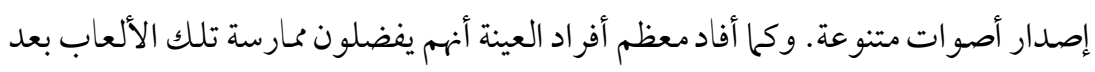
منتصف الليل إلى الصباح، في غياب من رقابة الأهل وأولياء الأمور. ع - عند الاجابة على السؤال: هل تساعد الألعاب الإلكترونية في نشر المقاطع الجنسية؟ كانت

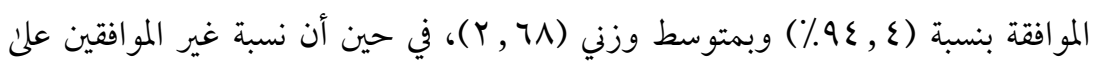


السؤال هي صفر. و تعد نسبة الموافقة علن السؤال كبيرة جدا، حيث يكاد يجمع أفراد العينة علن أن معظم الألعاب الإلكترونية تحتوي على المشاهد والمقاطع الجنسية، وصور للنساء في أوضاع غير أخلاقية، حيث تظهر المقاطع في المراحل المختلفة من اللعبة وفي أثناء اللعبة، مع إصدار أصوات متنوعة. كما أن بعض تلك الألعاب تتطلب من اللاعب ممارسة الرذيلة مع الشخصية الكرتونية باللعبة لكي ينتقل إلى المرحلة المتقدمة من اللعبة، كما أفاد بعض أفراد العينة بأنهم اعتادوا علن مشاهدة المو اقع الإباحية بسبب المقاطع الإباحية التي تحتويها الألعاب الإلكترونية.

ه- عند الاجابة علن السؤال: هل تشجع الألعاب الإلكترونية على ارتكاب جريمة الاغتصاب؟

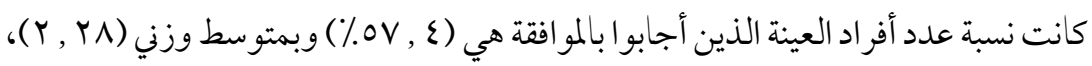
في حين كانت نسبة عدد أفراد العينة الذين أجابوا بعدم الموافقة علن السؤال هي (7 , ؟ ؟٪). وتعد نسبة عدد الأفراد الذين أجابو ابالمو افقة كبيرة (أكثر من النصف)، خصوصا في مثل تلك الجريمة الأخلاقية التي تتضمن الاعتداء على الغير بالإضافة إلى الانحراف الخلقي والقيمي لدى مرتكبيها. وربيا يفسر ذلك طبقا لما أفاد به بعض أفر اد العينة سابقامن أن معظم الألعاب الإلكترونية تحتوي علن المشاهد والمقاطع الجنسية، وصور للنساء في أوضاع غير أخلاقية، كما أن بعض تلك الألعاب تتطلب من اللاعب ممارسة الرذيلة مع الشخصية الكرتونية باللعبة لكي ينتقل إلى المرحلة المتقدمة من اللعبة، وأنهم يشاهدون المقاطع الإباحية ويتبادلونها فيما بينهم، كل تلك العو امل ربها تكون من الأسباب وراء محاولة تطبيق ما يشاهده اللاعبون في الألعاب الإلكترونية، وارتكاب جريمة الاغتصاب، إذا يعتبرها شجاعة وبطولة أن يقوم بعمل لا يقدر عليه إلا من يستطيع الوصول إلى المراحل المتقدمة من اللعبة. 
جدول (^) استجابات عينة الدراسة حول المحور الرابع (العنف)

\begin{tabular}{|c|c|c|c|c|c|c|c|c|}
\hline 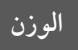 & & & & & & & & \\
\hline 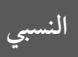 & $\%$ & ت & $\%$ & 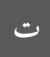 & $\%$ & 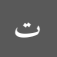 & 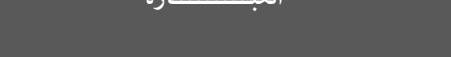 & $r$ \\
\hline$r, q 1$ & 1,1 & 1 & 0,7 & $r$ & $Q T, T$ & 0. & 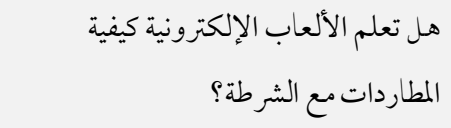 & 1 \\
\hline$r$, i & $1 \varepsilon, \wedge$ & $\wedge$ & 1,9 & 1 & $\wedge r, r$ & «o & هل تعلم الألعاب الإلكترونية المضاربات؟ & r \\
\hline$r, r r$ & $r_{0, q}$ & $1 \varepsilon$ & $1 \xi, \wedge$ & $\wedge$ & $\Delta q, r$ & $r r$ & هل هل تساعد الألعاب الإلكترونية في تعليم & r \\
\hline$r, r$. & $r r, r$ & 11 & ir. & $\mathrm{v}$ & or, $v$ & rq & كيفية الطعن؟ كاعد الألعاب الإلكترونية في تعليم & $\varepsilon$ \\
\hline$r, \sum \wedge$ & $r \varepsilon, 1$ & ir & $r, v$ & $r$ & $V r, r$ & $r q$ & هل تساعد الألعاب الإلكترونية في تعليم & 0 \\
\hline
\end{tabular}

1- عند الإجابة على السؤال: هل تعلم الألعاب الإلكترونية كيفية المطاردات مع الشرطة؟ كانت

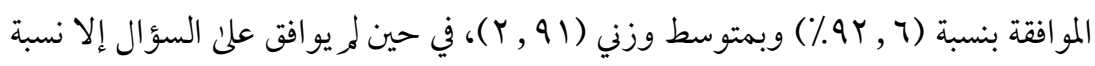

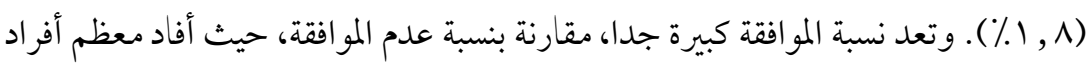

العينة بأن يفضلون الألعاب الإلكترونية التي تحتوي علن مطاردات لسيارات الشرطة،

ويستمتعون بأخذ سيارات الشرطة والتفحيط بها ثم تركها والهروب بعد صدمها. كما أفاد

أفراد العينة بأنهم يتنافسون فيما بينهم حول الوصول إلى مراحل متقدمة لمطاردات الشرطة،

وسرقة سيار اتهم لأنها تتمتع بمو اصفات خاصة، ويستطيعون القيام ببعض الحركات الخطرة

من خلالها.

r- عند الإجابة على السؤال: هل تعلم الألعاب الإلكترونية المضاربات؟ كانت الموافقة بنسبة

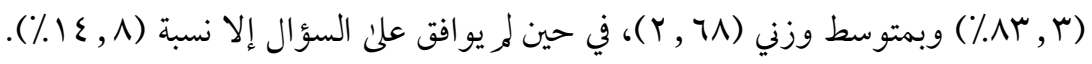


وتعد نسبة الموافقة كبيرة جدا، مقارنة بنسبة عدم المو افقة، حيث أفاد معظم أفر اد العينة بأنهم يقضون أوقاتا كثيرة في ألعاب المضاربات والتفحيط بالسيارات، ويتعلمون بعض الحركات العنيفة من خلال مر احل تلك الألعاب، وكيفية تنفيذ الضربة القاضية للخصم، والتعرف على الأماكن القاتلة من الجسم، و كيفية السيطرة علن الخصم، بل و القضاء عليه وقتله.

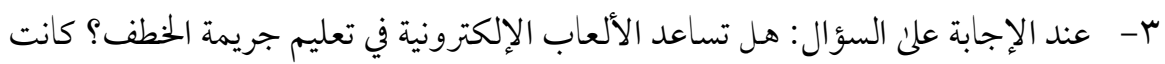

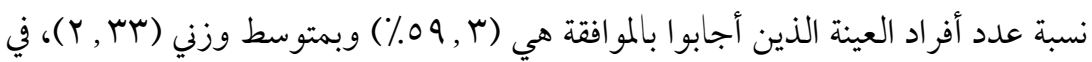

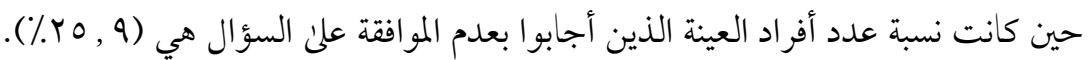
وتعد نسبة عدد الأفر اد الذين أجابوا بالمو افقة كبيرة (أكثر من النصف)، خصوصا في مثل تلك الجريمة الأخلاقية التي تتضمن الاعتداء علن الغير والتعدي علن حرمته، بالإضافة إلى الانحر اف الخلقي والقيمي لدئ مرتكبيها، إذ إن الغرض من الخطف في الغالب يكون بقصد ارتكاب الفاحشة مع المخطوف، فهي من الجرائم المركبة. وربها يفسر ذلك طبقا لما أفاد به بعض أفراد العينة سابقا من أن معظم الألعاب الإلكترونية تحتوي علن المشاهد والمقاطع الجنسية، وصور للنساء في أوضاع غير أخلاقية، كما أن بعض تلك الألعاب تتطلب من اللاعب ممارسة الرذيلة مع الشخصية الكرتونية باللعبة لكي ينتقل إلى المرحلة المتقدمة من اللعبة، مما يدفع بالبعض إلى محاولة تطبيق ما قام به من خلال الألعاب. ع - عند الإجابة علئ السؤ ال : هل تساعد الألعاب الإلكترونية في تعليم كيفية الطعن؟ كانت نسبة

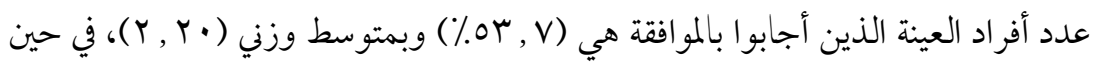
كانت نسبة عدد أفراد العينة الذين أجابوا بعدم المو افقة علن السؤال هي (r, rr/\%). وتعد نسبة عدد الأفراد الذين أجابوا بالمو افقة كبيرة (أكثر من النصف)، خصوصا في مثل تلك بك بكرئ الجريمة الأخلاقية التي تتضمن الاعتداء على حياة الغير. وربها يفسر ذلك بأن اللاعبين يفضلون ألعاب العنف والتي تحتوي علن مشاهد الطعن والقتل، حيث يرى البعض منهم أنه يتعلم كيفية الطعن ليحمي نفسه في حال المضاربات التي قد تحدث بين الشباب كثيرا. 
0- عند الإجابة على السؤال: هل تساعد الألعاب الإلكترونية في تعليم ارتكاب جريمة القتل؟

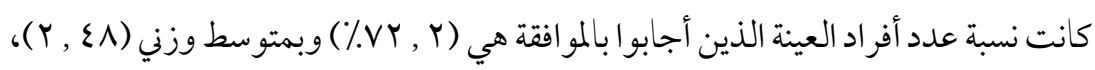
في حين كانت نسبة عدد أفراد العينة الذين أجابو ابعدم الموا افقة على السؤال هي (1 , ع ؟٪).

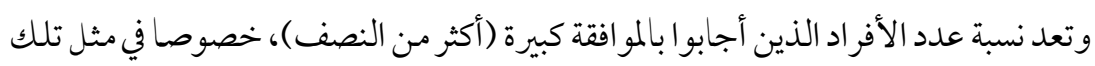
الجريمة الأخلاقية التي تتضمن الاعتداء علن حياة الآخرين بالإضافة إلى الانحراف الخلقي و القيمي لدى' مرتكبيها. وربيا يفسر ذلك طبقا لما أفاد به بعض أفر اد العينة سابقا من أن معظم أفراد العينة يفضلون الألعاب الإلكترونية التي تحتوي علن العنف والقتل باستخدام أسلحة متنوعة ومتطورة، حيث إن هناك بعض الألعاب التي تعتمد في مراحلها المتقدمة علن عدد القتلن من الأفراد، فكلما زاد عدد القتلن استطاع اللاعب أن يبدل سلاحه بآخر أكثر تطورا وفتكا ويتتل إلى المرحلة الأخرى التي تليها، وهكذا في باقي مراحل اللعبة.

$$
\text { رابعا: محور جر ائم السرقة: }
$$

جدول (9) استجابات عينة الدراسة حول المحور الخامس (السرقة)

\begin{tabular}{|c|c|c|c|c|c|c|c|c|}
\hline الوزن & & & & & & & & \\
\hline النسبي & $\%$ & ت & $\%$ & ت & $\%$ & ت & 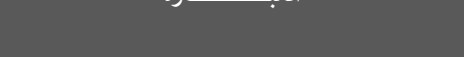 & r \\
\hline I, & 71,1 & $r r$ & 11,1 & T & $\mathrm{rv}, \mathrm{A}$ & 10 & المال من الأسرة؟ الألعاب الإلكترونية علن سرقة & 1 \\
\hline$r, r$. & ro, 9 & $1 \varepsilon$ & 11,0 & 1. & 00,7 & $r$. & سرقة المنازل؟ ال؟ الألعاب الإلكترونية في تعليم & r \\
\hline$r, 10$ & $r_{0, r}$ & 19 & $1 \varepsilon, \wedge$ & ^ & $0 \cdot$, & rv & المحلات التجارية؟ تساعد الألعاب الإلكترونية في السرقة من & $r$ \\
\hline$r, 79$ & $1 \varepsilon, \wedge$ & $\wedge$ & 1,9 & 1 & $\mu^{\mu}, r$ & so & السيارات؟ تشجع الألعاب الإلكترونية على سرقة & $\varepsilon$ \\
\hline
\end{tabular}




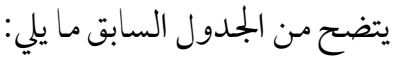

ا - عند الإجابة علن السؤال: هل تساعد الألعاب الإلكترونية علن سرقة المال من الأسرة؟ كانت

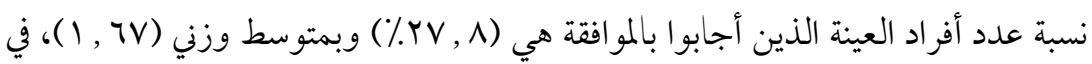

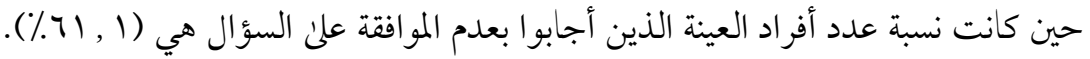

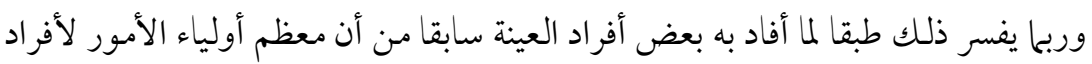

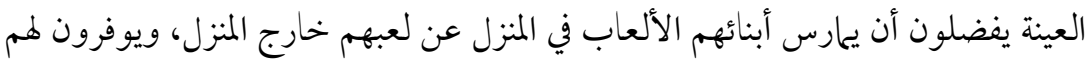
الألعاب ومتطلباتها، ليكونوا مر تبطين بالمنزل، وهو ما لا يدعو إلى السرقة من أفراد الأسرة.

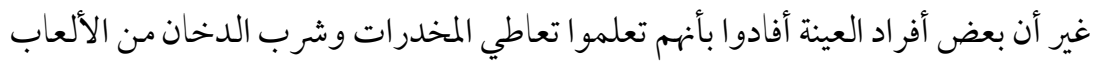

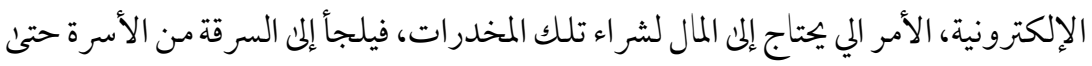

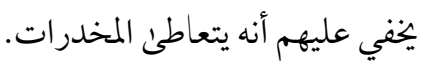

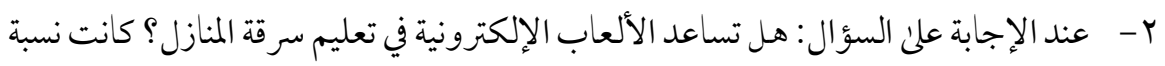

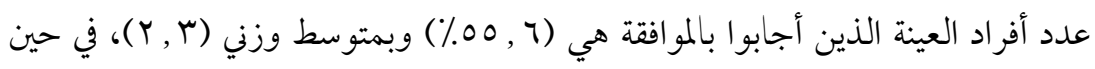

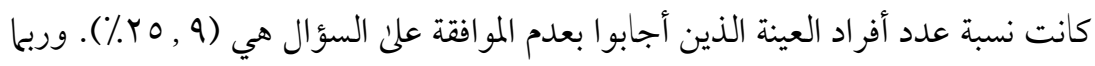

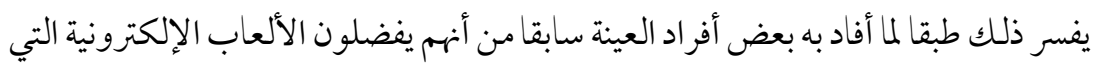

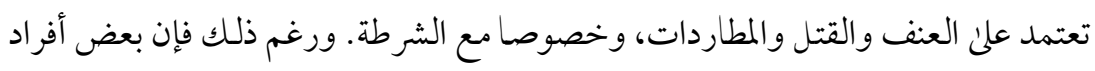

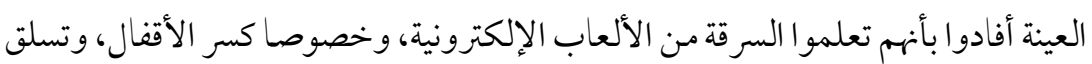

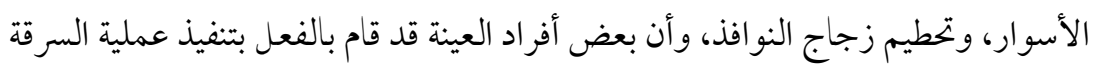

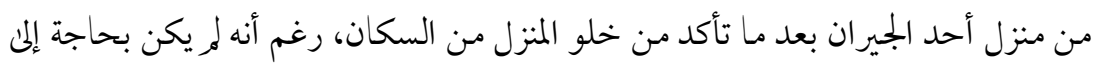

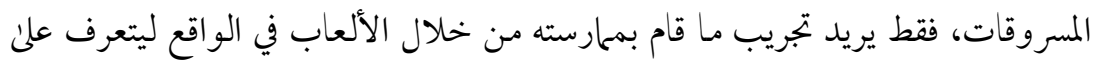

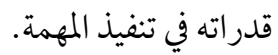

ץ- عند الإجابة علن السؤال: هل تساعد الألعاب الإلكترونية في السرقة من المحلات التجارية؟

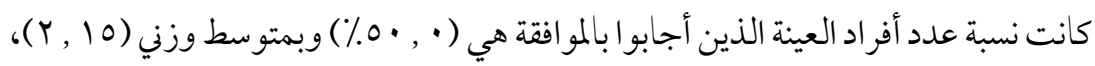

\section{http://dx.doi.org/10.29009/ijres.4.2.8}




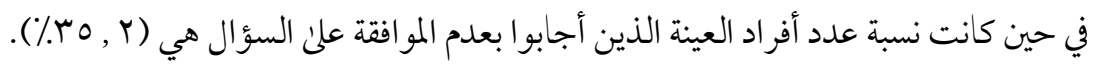
وريها يفسر ذلك بأن معظم أفراد العينة لر تكن احتياجاتهم مادية بالدرجة الأولن، ومع ذلك بلك

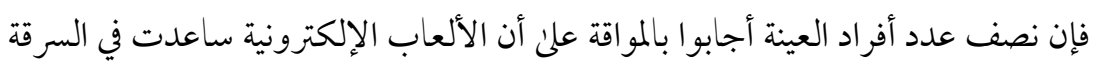
من المحلات التجارية، حيث أفادمعظم أفراد العينة بأنهم قاموا كثيرا بعمليات سرقة بسيطة لبعض المواد الغذائية مثل قطع الشوكولاتة والحلون وشواحن الجوالات، وذلك من البقالات التي لا تتوفر فيها كاميرات أو شبكات تلفزيونية للرقابة.

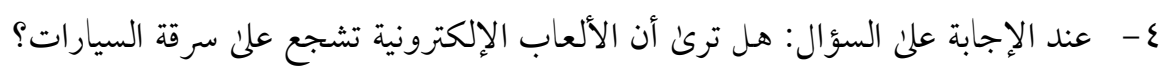

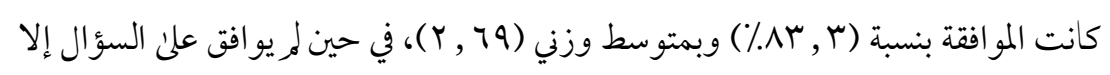
نسبة (^, ع ( ٪\%). وتعد نسبة الموافقة كبيرة جدا، مقارنة بنسبة عدم الموافقة، حيث أفاد معظم أفر اد العينة بأنهم يقضون أوقاتا كثيرة في ألعاب المضاربات والتفحيط بالسيارات، ويتعلمون منها الكثير من الحركات العنيفة بالسيارات من خلال مراحل تلك الألعاب، وأن عملية

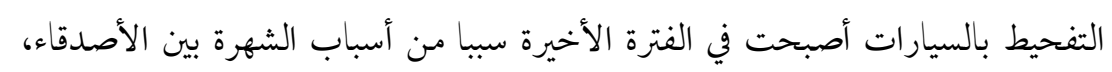
فيتعلمون من الألعاب الإلكترونية كيفية أداء تلك الحركات العنيفة بالسيارات، ثم يقومون

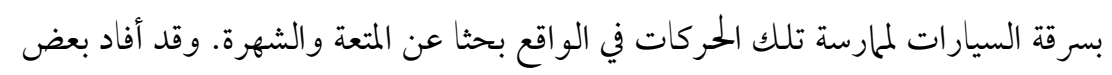
أفراد العينة أنهم تعلمو اكيفية سرقة السيارات من خلال الألعاب الإلكترونية.

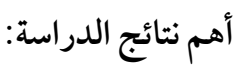

بناء على ما أفاد به أفر اد عينة الدراسة، وبعد تطبيق أداة الدراسة وتحليل نتائجها، فإن الدراسة الحالية خر جت بعدد من النتائج التي تتعلق بالعلاقة بين ممارسة الألعاب الإلكترونية وارتكاب الجرائم،

$$
\text { ولعل من أهم تلك النتائج ما يلي: }
$$

1 - لبعض الألعاب الإلكترونية دور كبير في تعليم شرب الدخان، وتعليم تعاطي المخدرات. r- تشجع بعض الألعاب الإلكترونية على تعاطي الحبوب المخدرة، وبيعها أو ترويجها. r- تساعد بعض الألعاب الإلكترونية في ارتكاب جريمة الابتزاز. 
ع - تعمل الكثير من الألعاب علن إثارة الغرائز الجلنسية من خلال احتوائها على صور ومقاطع

مخلة.

0 - تساعد الكثير من الألعاب الإلكترونية في نشر الصور والمقاطع الجنسية.

7- قد تشجع بعض الألعاب الإلكترونية على ارتكاب جريمة الاغتصاب.

- - - تعلم الكثير من الألعاب الإلكترونية كيفية المطاردات مع الشرطة.

1- - تساعد معظم الألعاب الإلكترونية في تعليم المضاربات الشخصية.

9- تساعد بعض الألعاب الإلكترونية في تعليم كل من الخطف والطعن والقتل.

• 1 - تساعد بعض الألعاب الإلكترونية في تعليم السرقة من الأسرة، أو من المنازل والسطو عليها.

11 - تساعد بعض الألعاب الإلكترونية في السرقة من المحلات التجارية.

r ا - تشجع بعض الألعاب الإلكترونية علئ سرقة السيارات و التفحيط بها.

التوصيات والمقترحات:

بعد الانتهاء من البحث، اتضح للباحث أن هناك الكثير من الألعاب الإلكترونية التي يمارسها

الشباب تتسبب في ارتكاب بعض الجرائم، وذلك طبقا لما أفادت به عينة الدراسة، وأن انتشار جرائم المخدرات والجرائم الأخلاقية ربها يكون من أسباب تداول الألعاب الإلكترونية وانتشارها بين الشباب، فضلا عن غياب دور الأسرة في الرقابة علن أبنائهم. ومسن هنا فإن الباحث يود أن يلفت أنظار أولياء الأمور والمربين والمخططين إلى ضرورة الانتباه إلى خطورة الألعاب الإلكترونية، وتخصيص جهة لمتابعة الألعاب الإلكترونية وتتبع مراحلها وما تحتويه من صور وعبارات، فضلا تتضمنه من سلوكيات خاطئة، تعود بالضرر علن الفرد والمجتمع. ويرئ الباحث أهمية تقديم بعض المقترحات والتوصيات لكل من الآباء والمربين وأولياء الأمور، قد تساعد في وقاية أبنائهم من الوقوع في الجرائم التي قد تكون

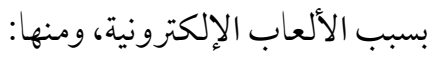

ا - ضرورة اشتراك الأبناء في حلقات تحفيظ القرآن الكريم، فهو حصن للأبناء في غياب الآباء. r - ضرورة اعطاء مساحة من الوقت لجلسات المناقشة والحوار بين كل من الآباء والأبناء. 
r- العمل علن مصاحبة الآبـاء لأبنائهم و التواصل مع أصدقائهم والتعرف عليهم. ع - توعية الآباء بالجو انب الإيجابية والسلبية للألعاب الإلكترونية.

0- متابعة أولياء الآباء لأبنائهم ومعرفة محتوئ الألعاب التي يقومون بممارستها. 7- عدم انشغال الآباء عن الأبناء لفترات زمنية طويلة، وضرورة المتابعة اليومية. - - - حرص الآباء علن ألا يمارس أبناءهم الألعاب الإلكترونية في غرف مغلقة.

1- تقليل فترات الألعاب والساعات التي يقضيها الأطفال في الألعاب الإلكترونية. 9- عدم السماح للأبناء بممارسة الألعاب الإلكترونية في فترات ما بعد منتصف الليل.

• 1 - تنمية هو اية القراءة في نفوس الأبناء، وعدم الاكتفاء بمحارسة الألعاب الإلكترونية. 11 - توعية الأبناء بخطورة وأضرار الجلوس لفترات طويلة أمام الأجهزة الإلكترونية دون تحرك. r ا - العمل علن إنتاج ألعاب الكترونية تتو افق مع قيم وثقافة المجتمع.

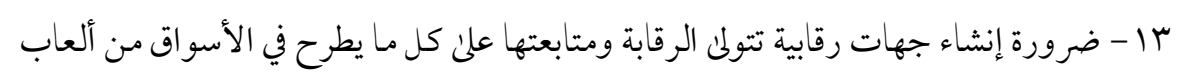
إلكترونية، وما يتم تداوله بين الشباب.

ع ا - حث علماء التربية وعلم النفس والاجتماع، والدين الإسلامي، والقانون علن إجراء البحوث النوعية حول كل ما يتعلق بالألعاب الإلكترونية وفق معايير قيم وثقافة المجتمع.

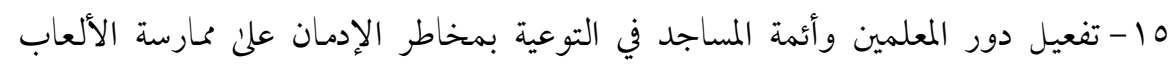
الإلكترونية، و التنبيه إلى ما فيها من محاذير. 17 - ضرورة متابعة الجهات الأمنية لمواقع الألعاب الإلكترونية، والعمل علن توعية الآباء من أضرارها وخطورتها. 


\section{المراجع العربية}

أبو وزنه، فلسطين علي حسن (11) (1). علاقة إدمان الألعاب الإلكترونية بالتكيف المدرسي والاجتماعي لدئ عينة من طلبة المرحلة الأساسية العليا في مديرية ععان الأولى.

$$
\text { ماجستير. غير منشورة. كلية الدراسات العليا. الجامعة الأردنية. }
$$

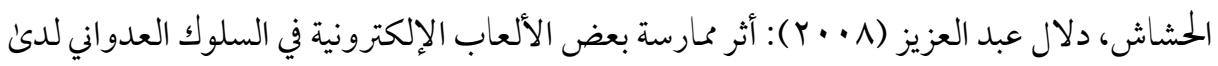
عينة من طلبة المرحلة الثانوية في المدارس الحكومية بدولة الكويت. ماجستير. غير بريك

$$
\text { منشورة. كلية الدراسات العليا. جامعة عحان العربية للدراسات العليا. }
$$

الرشود، متعب محمد مبارك (1 (1) (Y): واقع برامج التأهيل المهني في دور الملاحظة الاجتماعية من وجهة

$$
\text { نظر العاملين والنزلاء. ماجستير. غير منشورة. جامعة الإمام. }
$$

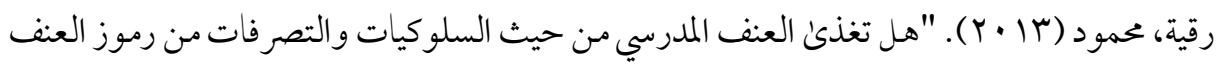
الافتراضي المتضمن الألعاب الإلكترونية العنيفة: قراءة تحليلية". مجلة الحكمة. ع ع r.

$$
\text { الجز ائر . مؤسسة كنوز الحكمة للنشر والتوزيع. }
$$

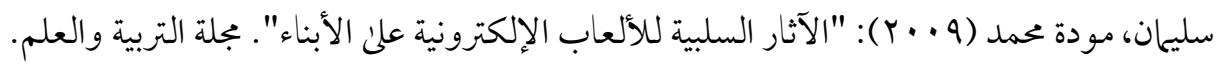

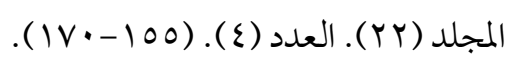

الشحروري، مها حسني (V · · r): أثر الألعاب الإلكترونية علن العمليات المعرفية والذكاء الانفعالي لدئ أطفال مرحلة الطفولة المتوسطة في الأردن، دكتوراه. غير منشورة. كلية

$$
\text { الدراسات التربوية العليا. جامعة عمان العربية للدراسات العليا. }
$$

فليه، فاروق عبده و الزكي، أحمد عبد الفتاح (ع · · ) : معجم مصطلحات التربية لفظا واصطلاحا. دار

$$
\text { الوفاء للطباعة والنشر ـ مصر. الاسكندرية. }
$$

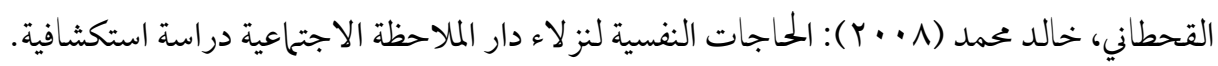

ماجستير. غير منشورة. كلية الدراسات العليا. جامعة نايف العربية للعلوم الأمنية.

\section{http://dx.doi.org/10.29009/ijres.4.2.8}


القضاة، علي منعم (rا • Y): التواصل الانساني (بين ثورة اللغة وعصر الديييتال). المملكة العربية

$$
\text { السعودية. الدمام المتنبي. }
$$

مطاوع، ضياء الدين محمد ( . . ( ). "فعالية الألعاب الكمبيوترية في تحصيل التلاميذ معسري القراءة (الدسلكسيين) لبعض مفاهيم العلوم بالمرحلة المتوسطة في المملكة العربية السعودية".

$$
\text { أطفال الخليج ذوي الاحتياجات الخاصة. (www.gulfkids.com) (1- (1) ع ). }
$$

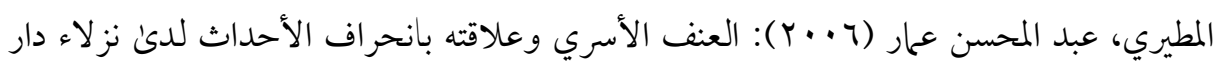
الملاحظة الاجتماعية بمدينة الرياض. ماجستير. غير منشورة. كلية الدراسات العليا.

$$
\text { جامعة نايف العربية للعلوم الأمنية. }
$$

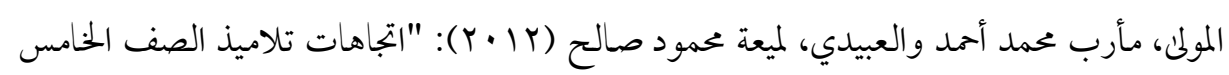

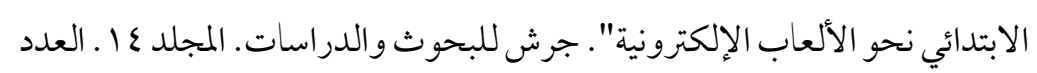

$$
(7 r \Lambda-r \cdot 0) r
$$

وزارة الشؤون الاجتماعية (عץعاهـ): دور الملاحظة الاجتماعي. نشرة وكالة الوزارة للشؤون

$$
\text { الاجتماعية. الرياض. }
$$

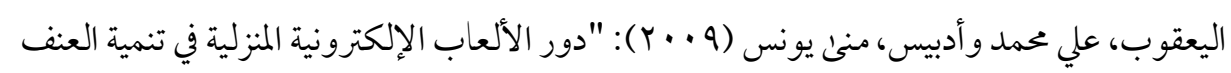
لدئ طفل الدراسة الابتدائية بدولة الكويت". مجلة مستقبل التربية العربية. العدد

$$
\text { (ON) }
$$




\section{References:}

Abu Wazanah, Palestine Ali Hassan (2011): The relationship of electronic games addiction to school and social adjustment among a sample of students from the upper basic stage in the first Amman Directorate. Unpublished M.A. College of Graduate Studies. University of Jordan. (In Arabic).

Al-Hashash, Dalal Abdul-Aziz (2008): The effect of playing some electronic games on the aggressive behavior of a sample of high school students in government schools in the State of Kuwait. Unpublished M.A. College of Graduate Studies. Amman Arab University for Graduate Studies. (In Arabic).

Alkodah, Ali Menem (2013): Human Communication (between the Language Revolution and the Digital Age). Kingdom of Saudi Arabia. Dammam. Mutanabbi. (In Arabic).

Al-Mutairi, Abdel Mohsen Ammar (2006): family violence and its relationship. (In Arabic).

Al-Qahtani, Khaled Muhammad (2008): The psychological needs of Dar Al Molahza Al Egtemaeaa inmates, an exploratory study. Unpublished M.A. College of Graduate Studies. Naif Arab University for Security Sciences.". (In Arabic).

Al-Rashoud, Miteb Mohamed Mubarak (2011): The reality of vocational rehabilitation programs in the role of social observation from the viewpoint of workers and inmates Unpublished M.A. Imam Ruqayyah University. (In Arabic).

Al-Shahrouri, Maha Hosni (2007): The effect of electronic games on cognitive processes and emotional intelligence among middle-school children in Jordan, Unpublished Ph.D. College of Graduate Studies. Amman Arab University for Graduate Studies. (In Arabic).

Flih, Farouq Abdo and Al-Zaki, Ahmed Abdel-Fattah (2004): A dictionary of the terminology of education, verbally and idiomatically. Dar Al-Wafaa for Printing and Publishing. Egypt. Alexandria. (In Arabic). 
Mahmoud (2013). "Was school violence fueled in terms of behavior from the symbols of virtual violence involving violent electronic games: an analytical reading. Al Hikma Magazine. version 28. Algeria. Kunooz Al Hikma Foundation for Publishing and Distribution. (In Arabic).

Mutawa, Diaa Al-Din Muhammad (2000). "The effectiveness of computer games in achieving dyslexic students for some concepts of middle school science in the Kingdom of Saudi Arabia." Gulf kids with special needs (www.gulfkids.com) (1-48). (In Arabic).

Sharma, B., Harker, M., Harker, D., \& Reinhard, K. (2010). Youth transition to university in Germany and Australia: an empirical investigation of healthy eating behaviour. Journal of Youth Studies, 13(3), 353-367. doi: 10.1080/13676260903447510.

Suleiman, Mawaddah Muhammad (2009): "The negative effects of electronic games on children." Education and Science Magazine. Vol (22). version (4). (155-170). (In Arabic).

Trout Josh \& Christie Brett (2007) Interactive Video Games in Physical Education: Rather Than Contribute to a Sedentary Lifestyle, These Games Demand Activity from the Players. The Journal of Physical Education, Recreation \& Dance. Volume: 78. Issue: 5. American Alliance for Health, Physical Education, Recreation and Dance 